\title{
METODOLOGIAS ATIVAS NA PÓS- GRADUAÇÃO: RELATO DE CASO NA DISCIPLINA EDUCAÇÃO AMBIENTAL PARA A SUSTENTABILIDADE
}

\author{
Regina Lúcia Félix de Aguiar Lima ${ }^{1}$ \\ Alessandra Gomes Marques Pacheco ${ }^{2}$ \\ Elâine Maria dos Santos Ribeiro ${ }^{3}$
}

Resumo: A aprendizagem invertida é uma metodologia ativa que possibilita a construção de conhecimentos de forma significativa e rompe barreiras físicas, geográficas e temporais. Nesse relato de caso visamos descrever a inversão da disciplina Educação Ambiental para a Sustentabilidade e aprendizagem baseada em projeto. A organização da disciplina foi feita seguindo o Guia para Utilização da Aprendizagem Invertida no Ensino Superior, de Robert Talbert. A experiência com a aprendizagem invertida, pactuada por docentes e discentes do mestrado em Ciência e Tecnologia Ambiental e viabilizada por tecnologias de informação e comunicação, foi exitosa frente ao desafio educacional enfrentado no contexto da pandemia causada pela Covid-19.

Palavras-chave: Aprendizagem Invertida; Educação remota; TIC; Educação em tempos de Covid19; Ensino on-line.

Abstract: Flipped Learning is an active methodology that enables the construction of knowledge in a meaningful way and breaks physical, geographical and temporal barriers. This case report aims to describe the inversion of the discipline Environmental Education for Sustainability and project-based learning. The course was organized according to the Robert Talbert book Flipped learning: a guide for higher education faculty. The experience with inverted learning, agreed by teachers and students of the Master in Environmental Science and Technology and made possible by information and communication technologies, was successful in the face of the educational challenge faced in the context of the pandemic caused by Covid- 19 .

Keywords: Flipped Learning; Remote education; ICT; Education in the time of Covid19; Online discipline.

\footnotetext{
1 Universidade de Pernambuco. E-mail: regina.aguiar@upe.br. http://lattes.cnpq.br/8549101690272163

2 Secretaria de Municipal de Educação de Petrolina. E-mail: alessandragmarques@hotmail.com http://lattes.cnpq.br/1107755893527804

3 Universidade de Pernambuco. E-mail: elaine.ribeiro@upe.br. http://lattes.cnpq.br/3304685448889789 


\section{Introdução}

A comunicação é uma das principais necessidades do ser humano desde o aparecimento da humanidade. Ao longo da história, podem ser evidenciados registros de como a evolução na comunicação impactou e mudou o mundo contemporâneo. Essas mudanças, que podem ser evidenciadas em diferentes áreas do conhecimento, vão se interligando e passam a ser responsáveis por alterações significativas no modelo educacional tradicional. $O$ desenvolvimento das tecnologias de informação e comunicação (TICs), na forma de equipamentos e funções, possibilitou novas formas lidar com as informações. O uso combinado de TICs, modelos modernos de ensino e metodologias ativas no processo educacional é desafiador e estratégico para a inovação pedagógica (BACICH; MORAN, 2018, SOARES-LEITE; NASCIMENTO-RIBEIRO, 2011).

Diante desse contexto, o perfil, tanto dos docentes quanto de discentes, e os métodos de ensino ganharam novas abordagens com a utilização de Metodologias Ativas de aprendizagem, como a Aprendizagem Invertida (ou flipped learning, no Inglês) (BACICH; MORAN, 2018; CAMARGO; DAROS, 2018; TALBERT, 2019). Embora seja uma metodologia relativamente nova, quando comparada a outras metodologias de aprendizagem, ela é considerada muito promissora e capaz de renovar procedimentos educacionais tradicionais, visto que utiliza estratégias de aprendizagem orientadas pelo docente e metodologias construtivistas centradas na reflexão, ação e prática dos estudantes. Essa prática pedagógica vem sendo implementada em distintos níveis e institutos de educação de diversos países (FLN, 2014; VALENTE, 2014; LO; HEW, 2017).

O desenvolvimento do modelo de Aprendizagem Invertida teve suas bases na década de 1990, a partir de três experiências independentes de reformulação de disciplinas realizadas por Erick Mazur com o Peer instruction na Universidade de Harvard; por J. Wesley Baker com um método instrucional denominado sala de aula invertida na Cedarville University; e por Maureen Lage, Glenn Platt e Michael Treglia com uso de uma variedade de métodos de ensino numa proposta também denominada sala de aula invertida na Universidade de Miami (TALBERT; 2019). A experiência de Mazur teve resultados publicados no livro "Peer instruction: a user's manual", em 1997. Nesse livro, o autor apresenta um design de disciplina e instrução denominado peer instruction, que é considerado, atualmente, um exemplo de aprendizagem invertida. Baker, em março de 2000, apresentou numa conferência sua visão de aprendizagem invertida, usando o termo sala de aula invertida para descrevê-la (BAKER, 2000). Ainda em 2000, o conceito de sala de aula invertida (flipped classroom) tomou dimensões expressivas com a publicação do artigo de Lage, Platt e Treglia quando foram demonstrados resultados positivos com o uso dessa nova estratégia de aprendizagem (LAGE et al. 2000; TALBERT, 2019). A metodologia da sala de aula invertida se popularizou e se difundiu com Salmann Khan, que começou a produzir e disponibilizar videoaulas, fundando a Khan Academy, e com Jon Bergmann e Aaron Sams

revista brasileira educação ambiental 
em palestras sobre a aplicação de instrução invertida feitas em workshops para professores (TALBERT, 2019; TREVELIN et al. 2013).

Dessa forma, surgiu o que conhecemos como Aprendizagem Invertida, metodologia que expande o acesso à educação de forma significativa, pois, ao romper barreiras físicas, geográficas e temporais, revela um panorama educativo, no qual o acesso ao conhecimento torna-se cada vez mais inclusivo, sendo capaz de promover a autonomia e responsabilidade do estudante, tornando-o centro ativo das ações educativas e, consequentemente, protagonista do seu processo de aprendizagem. Entretanto, essa nova concepção de ensino-aprendizagem, focada em adquirir conhecimento em leituras que antecipam a aula, exige, também, modificações voltadas à criatividade e flexibilidade junto à docência (ABEYSEKERA; DAWSON, 2015). Para O'Flaherty e Phillips (2015), a adoção da sala de aula invertida retira aluno e professor de suas zonas de conforto; coloca-os em situação de desafios necessários, pois o estabelecimento dessas mudanças expande as possibilidades de comunicação e pesquisas, além de produzir novas competências.

Os modelos de ensino atuais podem ser divididos basicamente em duas categorias, tradicional e os modernos (DEMIREL, 2016). O modelo tradicional de ensino, caracterizado por ter o professor como o centro do processo de ensino, fazendo a transmissão de conhecimento com participação limitada/passiva do aluno. Durante as aulas, são apresentados novos conteúdos aos alunos. Geralmente, a metodologia usada para isso é a aula expositiva. Após as aulas, são atribuídas tarefas aos alunos, geralmente, caracterizadas pelo maior grau de complexidade, destinadas à realização individual e sem suporte do professor. Por outro lado, no modelo invertido, a introdução de novos conteúdos acontece antes da aula, com a aplicação de tarefas de baixa a média complexidade e, durante a aula, são realizadas tarefas mais complexas que podem ter suporte do professor e de colegas para isso, geralmente, com uso de metodologias ativas. Nesse modelo, o aluno passa a ser o centro do processo de ensino, está ativamente envolvido no processo de aprendizagem e se torna consciente e responsável pelo seu próprio aprendizado, o que Ihe proporciona autoconfiança, autoconsciência, responsabilidade e autonomia (DEMIREL, 2016; TALBERT, 2019). A aprendizagem invertida é um método moderno com uma abordagem pedagógica em que a instrução direta não ocorre em espaços coletivos; ela ocorre de forma individual pelo estudante, e o espaço do grupo é transformado em um dinâmico e interativo ambiente de aprendizagem onde o educador orienta os alunos sobre as formas de aplicar conceitos e a se envolverem criativamente no assunto (FLN, 2014; LO; HEW, 2017).

As TICs são importantes também para outros aspectos educacionais, como para a realização de aulas ou disciplinas remotas (on-line), ou como alternativa às aulas e disciplinas presenciais; também em atividades síncronas, quando os alunos participam da aula ao mesmo tempo, ou assíncronas, quando não há encontros fixos com os alunos (TALBERT, 2019). As 
tecnologias disponíveis têm viabilizado a realização de disciplinas on-line e híbridas no ensino superior, mas, no contexto da suspensão de atividades presenciais nas universidades imposta pela pandemia causada pela Covid-19, essa opção por aulas online e metodologias ativas passou a ser imperativa. Assim, no contexto de uma crise deve-se buscar a compreender as novas situações que se apresentam e atuar nos espaços de aprendizagem, com a adoção de novas soluções (GUERRA et al., 2020). Assim, neste artigo, apresentamos a reformulação da disciplina Educação Ambiental e Sustentabilidade do Programa de Pós-graduação em Ciência e Tecnologia Ambiental (PPGCTA) da Universidade de Pernambuco Campus Petrolina, que teve como base a utilização da aprendizagem invertida e planejamento para ser ministrada de forma remota (on-line) com tempos de realização síncrono e assíncrono.

\section{Material e métodos}

\section{Contexto da inversão da disciplina}

A mudança da disciplina do modelo tradicional para o invertido aconteceu em vista da suspensão de atividades de ensino decorrente das ações para pandemia de Covid-19. A suspensão das aulas presenciais na Universidade de Pernambuco (UPE) foi determinada em março de 2020, dias antes do início das aulas no curso de mestrado do PPGCTA. A perspectiva inicial sobre a duração da suspensão das atividades era de que seria revertida em um prazo relativamente curto, de até dois meses. No decorrer do tempo, essa percepção se alterou e foi facultada aos programas de pós-graduação a realização de disciplinas on-line, com aulas remotas, desde que os professores das disciplinas considerassem que seria adequado adotar a modalidade de ensino remoto.

Assim, na disciplina Educação Ambiental para Sustentabilidade, além do desafio para a realização em formato on-line, optou-se por adotar a metodologia da aprendizagem invertida. A escolha da utilização da aprendizagem invertida foi feita com base em estudo sobre o modelo e a percepção do seu potencial para usar o tempo em aula, agora virtual, criando um ambiente de aprendizagem centrado no aluno para favorecer a aprendizagem significativa e desenvolver participação, emancipação, que são alguns dos aspectos chave da Educação Ambiental crítica (LAYRARGUES; LIMA, 2014). Desde 2017, a disciplina estava sendo ministrada em modelo tradicional, presencial, com atividades síncronas e assíncronas, com metodologias tradicionais (aulas expositivas) e ativas (discussão, seminário, aprendizagem baseada em projetos).

A reformulação da disciplina para o modelo invertido foi feita seguindo o livro "Guia para Utilização da Aprendizagem Invertida no Ensino Superior" do autor Robert Talbert (2019). O planejamento da disciplina passou pela elaboração dos objetivos de aprendizagem de cada conteúdo, planejamento e 
desenvolvimento de atividades para o trabalho no espaço do grupo e, a partir daí, o planejamento e desenvolvimento de atividades para o trabalho nos espaços individual e pós-grupo.

No planejamento da aprendizagem invertida, a formulação dos objetivos de aprendizagem foi uma questão central para definir as atividades da disciplina, as estratégias de ensino e a integração dessas partes para produzir aprendizagem integrada e significativa para os estudantes. Os objetivos da disciplina foram elaborados com base na taxonomia de Bloom (ANDERSON et al. 2001; FERRAZ; BELHOT 2010; TALBERT 2019).

\section{Inversão da disciplina Educação Ambiental para a Sustentabilidade}

Foram selecionados artigos, livros, documentos e preparadas atividades para uso no espaço individual pelos alunos e para a abordagem inicial dos conteúdos de caráter teórico da disciplina, que são: Educação Ambiental: características e histórico, Agenda 2030 e legislação ambiental brasileira. O material de cada conteúdo foi incluído no plano da disciplina reformulado, contendo uma descrição também das atividades que foram desenvolvidas e do processo de avaliação (Quadro 1). Foram usadas referências de livros e artigos que estivessem disponíveis on-line.

Para a etapa de planejamento e elaboração dos projetos de Educação Ambiental, foi apresentado aos discentes o projeto em andamento "Aprendendo sobre o valor da biodiversidade da Caatinga e seus serviços ecossistêmicos no ensino escolar" e, a seguir, os alunos foram convidados a elaborar propostas de subprojetos com a temática desse projeto que contemplassem também os conteúdos teóricos abordados na primeira parte da disciplina. O projeto "Aprendendo sobre o valor da biodiversidade da Caatinga e seus serviços ecossistêmicos no ensino escolar" financiado pela Fundação de Amparo à Pesquisa de Pernambuco - FACEPE (APQ - 0177-2.05/18), que tem como um de seus objetivos a criação e testagem de recursos didáticos voltados à educação básica. Especificamente, os discentes teriam como tarefa a elaboração de subprojetos para produção de recurso didático relacionado ao tema apresentado. Inicialmente, foi realizada a apresentação da proposta maior e das possibilidades de participação dos estudantes e verificação da concordância deles. Posteriormente, seguiu-se a organização dos alunos em grupos e divisão dos temas dos projetos para elaboração e sistematização na forma de artigo.

\section{Resultados e discussão}

O plano de ensino da disciplina Educação Ambiental para a Sustentabilidade, foi reformulado com a utilização da metodologia de aprendizagem invertida (Quadro 1). Ele está constituído das mesmas seções de um plano de ensino do modelo tradicional, somente as seções ementa e 
conteúdo programático não tiveram alterações em relação ao plano adotado em anos anteriores. A mudança mais profunda foi na seção de procedimentos didáticos, havendo a necessidade de formular um documento adicional com a descrição das atividades de cada conteúdo da disciplina (Quadro 2).

Quadro 1. Plano de ensino da disciplina Educação Ambiental para a Sustentabilidade.

\section{Ementa}

Estudo da Educação Ambiental, a partir do histórico, suas características e os objetivos do desenvolvimento sustentável previstos na Agenda 2030 da Organização das Nações Unidas. Estudo da legislação brasileira relacionada às questões ambientais, com destaque para Política Nacional de Educação Ambiental. Contribuição para avanços na agenda ambiental brasileira, com projetos de Educação Ambiental voltados à educação básica.

\section{Conteúdo Programático}

1. Educação Ambiental: características e histórico.

2. Agenda 2030 e Objetivos do desenvolvimento sustentável (ODS).

3. Legislação ambiental brasileira e Política Nacional de Educação Ambiental

4. Projetos em Educação Ambiental para a educação básica.

\section{Procedimentos Didáticos}

No estudo do conteúdo programático, são utilizadas estratégias de aprendizagem invertida, com atividades em espaço individual, em espaço de grupo e em espaço pós-grupo.

No espaço individual, são atribuídas atividades aos discentes, acompanhadas de orientações e materiais de estudo na plataforma Google Classroom. As atividades deverão ser realizadas individual ou coletivamente. Neste último caso, os grupos se reúnem também online, em momento anterior ao espaço de grupo (discentes e docentes).

O espaço de grupo acontece em encontros on-line, síncronos, usando a plataforma Google Meet, os quais são gravados e disponibilizados aos alunos para garantir a todos o acesso às aulas em sua completude, visto que a qualidade do sinal de internet pode ser variável para alguns discentes.

Os conteúdos 1, 2, 3 e 4 foram abordados em atividades de aprendizagem atribuídas nos espaços individual e/ou de grupo e/ou pós-grupo, a serem realizadas conforme os procedimentos e referências apresentadas no cronograma.

A atividade relativa ao conteúdo 4 consiste na elaboração/reelaboração de projetos de Educação Ambiental em grupos. Inicialmente, os discentes irão elaborar uma proposta de projeto, e, posteriormente, em um momento coletivo, essa proposta será discutida entre discentes e docentes da disciplina. As propostas didáticas desenvolvidas a partir dos projetos poderão ser executadas em escolas da educação básica e como parte de cursos de capacitação para professores da educação básica.

\section{Avaliação}

A nota final na disciplina é a média ponderada das atividades dos tópicos 1, 2, 3 e 4, com valor máximo de cada atividade igual a 10 pontos. Será APROVADO o aluno que obtiver nota final $\geq 7,0$ e participação efetiva nas atividades.

Peso das atividades relativas aos conteúdos 1 e $2=1,5$

Peso da atividade do conteúdo $3=1$

Peso da atividade do conteúdo $4=6$

\section{Recursos Didáticos}

Plataformas Google meet e Google classroom, E-Books gratuitos disponíveis on-line, artigos científicos disponíveis on-line, arquivos em power point. 


\section{Referências}

1. CARSON, R.L. Primavera Silenciosa. $2^{2}$ ed. São Paulo: Melhoramentos, 1969.

2. BARBOSA, K.L.; ANDRADE, L.N. VIANNA, U.R. O desenvolvimento sustentável e as Instituições de Ensino Superior. In: Vianna, U.R.; Carvalho, J.R. Memórias em gestão pública. Alegre, ES: CAUFES. 2017.

3. SORNBERGER, N.A. et al. A consolidação do movimento ambientalista e da educação ambiental no Brasil e no mundo: algumas perspectivas históricas. Revista Eletrônica do Mestrado em Educação Ambiental, p. 301-317, 2014.

4. BRASIL. Transformando nosso mundo: a agenda 2030 para o desenvolvimento sustentável. 2016.

5. COSTA, P.; COSTA, J.R.; WANDELLI, E.V.; BIANCHINI, F.; TAVARES, E.D. Erradicação da pobreza: contribuições da Embrapa. Brasília: Embrapa. (ODS 1), 2012.

6. MEDEIROS, C. A.B.; BUENO, Y. M.; SÁ, T.D.A.; VIDAL, M.C.; ESPINDOLA, J.A.A. Fome zero e agricultura sustentável: contribuições da Embrapa. Brasília: Embrapa. (ODS 2), 2018. 7. KIILL, L.H.P.; KATO, H.C.G.A.; CALEGARIO, F.F. Saúde e bem-estar: contribuições da Embrapa. Brasília: Embrapa. (ODS 3), 2018.

8. COSTA, J.R.; COSTA, P.; HAMMES, V.S.; AQUINO, A.M. Educação de qualidade: contribuições da Embrapa. Brasília: Embrapa. (ODS 4), 2012.

9. ARZABE, C.; COSTA, V.C. Igualdade de gênero: contribuições da Embrapa. Brasília: Embrapa. 2018. (ODS 5), 2018.

10. SILVA, M.S.L.; MATTHIENSEN, A.; BRITO, L.T.L.; LIMA, J.E.F.W.; CARVALHO, C.J.R. Água e saneamento: contribuições da Embrapa. Brasília: Embrapa. (ODS 6), 2018.

11. KUNZ, A.; OTENIO, M.H.; LEITÃO, R.C.; GAMBETTA, R. Energia limpa e acessível: contribuições da Embrapa. Brasília: Embrapa. (ODS 7), 2012.

12. MELLO, L.M.R.; BASSI, N.S.S.; SANTOS, L.A.; GERUM, A.F.A.A. Trabalho decente e crescimento econômico: contribuições da Embrapa. Brasília: Embrapa. (ODS 8), 2018.

13. KROLOW, A.C.R.; NALERIO, E.S.; SAMARY, F.T.; LIMA, L.K.F. Indústria, inovação e infraestrutura: contribuições da Embrapa. Brasília: Embrapa. (ODS 9), 2018.

14. DIAS, T.A.B.; UDRY, M.C.F.V.; HEBERLE, A.L.O.; NOGUEIRA, J.D. Redução das desigualdades: contribuições da Embrapa. Brasília: Embrapa. (ODS 10), 2018.

15. COSTA, J. R.; COSTA, P.; ALMEIDA, J. S. S. E.; HAMMES, V. S. Cidades e comunidades sustentáveis: contribuições da Embrapa. Brasília: Embrapa. (ODS 11) 2018.

16. PALHARES, J.C.P.; OLIVEIRA, V.B.V.; FREIRE JUNIOR, M.; CERDEIRA A.L.; PRADO, H.A. Consumo e produção responsáveis: contribuições da Embrapa. Brasília: Embrapa. (ODS 12), 2018.

17. CUADRA, S.V.; HEINEMANN, A.B.; BARIONI, L.G.; MOZZER, G.B.; BERGIER, I. Ação contra a mudança global do clima: contribuições da Embrapa. Brasília: Embrapa. (ODS 13), 2018.

18. FOGAÇA, F.H.S.; FURTADO, A.A.L.; SILVA, C.A.; TAVARES-DIAS, M.; ROUTLEDGE, E. A. B. Vida na água: contribuições da Embrapa. Brasília: Embrapa. (ODS 14), 2018.

19. VILELA, G.F.; BENTES, M.P.M.; OLIVEIRA, Y.M.M.; MARQUES, D.K.S.; SILVA J.C.B. Vida terrestre: contribuições da Embrapa. Brasília: Embrapa. (ODS 15), 2018.

20. DINIZ, F.H.; STUCHI, J.F.; NASCIMENTO, P.P.; BORBA, M.F.S. Paz, justiça e instituições eficazes: contribuições da Embrapa. Brasília: Embrapa. (ODS 16), 2018.

21. GOIS, S.L.L.; PEREIRA, M.A.; MELO, P.E.; TAVARES, S.C.C.H.; DRUMOND, P.M. Parcerias e meios de implementação: contribuições da Embrapa. Brasília: Embrapa. (ODS 17), 2018.

22. MILLER G.T.J. Ciência Ambiental. 11aㅗ ed. São Paulo: Cengage Learning, 2012.

23. BRASIL. Lei n. 9795 - 27 de abril de 1999. Dispõe sobre a educação ambiental. Política Nacional de Educação Ambiental. Brasília, 1999.

24. PEREIRA, P.H.S.; TERZI A.M. Aspectos gerais da Lei de Educação Ambiental e a problemática da transversalidade em sua aplicação nas escolas. Revista Âmbito Jurídico. Rio Grande, XIII, n. 75, 2010.

25. HAMMES, V.S. Proposta metodológica da macroeducação. In: Série Educação ambiental para o desenvolvimento sustentável. v 2. Brasília: Embrapa. 2012. 
26. HAMMES, V.S. Ver: percepção do diagnóstico ambiental. In: Série Educação ambiental para o desenvolvimento sustentável. v 3. Brasília: Embrapa. 2012.

27 HAMMES, V.S. Julgar: percepção do diagnóstico ambiental. In: Série Educação ambiental para o desenvolvimento sustentável. v 4. Brasília: Embrapa. 2012.

28. HAMMES, V.S. Agir: percepção do diagnóstico ambiental. In: Série Educação ambiental para o desenvolvimento sustentável. v 5. Brasília: Embrapa. 2012.

29. HAMMES, V.S.; RACHWAL, M.F.G. Meio ambiente e a escola. In: Série Educação ambiental para o desenvolvimento sustentável. v 7. Brasília: Embrapa. 2012.

30. MMA. Ministério do Meio Ambiente. Encontros e caminhos: formação de educadoras(es) ambientais e coletivos educadores. Brasília: MMA/Departamento de Educação Ambiental, 2. 2007.

Fonte: Autoria própria.

O processo de reformulação da disciplina precisou ser ajustado, pois havia a expectativa de retorno das atividades de ensino nas escolas da rede pública e, nesse contexto, estava prevista a execução dos projetos elaborados pelos estudantes da disciplina. Contudo, no decorrer do tempo, verificou-se que a duração da suspensão das atividades poderia se estender por um longo período. Assim, foi necessário modificar 0 desfecho da atividade 4 (Projetos/Propostas em Educação Ambiental para a educação básica), que foi modificada para a elaboração de artigos a partir do desenvolvimento dos subprojetos para publicação que abrangesse as principais questões ambientais da Caatinga.

A inversão da disciplina foi norteada conforme as instruções do "Guia para Utilização da Aprendizagem Invertida no Ensino Superior" de Robert Talbert (2019), que permitiu o conhecimento amplo sobre a metodologia aprendizagem invertida, com apresentação da teoria e a descrição de várias experiências de inversão de disciplinas (tanto de sucesso quanto de fracassos), apresentação do ponto de vista de docentes e discentes, dos problemas frequentes, dos passos a seguir na inversão e das ferramentas tecnológicas para viabilizar atividades nos espaços de aprendizagem. Enfim, o guia proporcionou um conjunto de informações robusto e completo para suporte efetivo da inversão, sendo uma leitura recomendada aos docentes que desejem adotar essa metodologia em suas disciplinas.

Quadro 2: Descrição das atividades da disciplina.

\footnotetext{
Atividade 1 - Educação Ambiental: características e histórico

Espaço individual: trabalho discente visando conhecer o contexto da questão ambiental e os desdobramentos em esfera mundial e local.

Realização das seguintes leituras:

- Capítulos 1 e 17 do livro Primavera silenciosa da autora Rachel Carson (Carson, 1969) e da biografia da autora (página 257, Miller, 2012).

- Textos de Barbosa et al. (2017), e Sornberger et al. (2014), sobre histórico dos movimentos ambientalistas com vistas a relacionar o movimento ambientalista e a área de Ciências Ambientais da CAPES.

Espaço do grupo: Aula síncrona na plataforma Google Meet, duração 3 horas.

- Apresentação do plano da disciplina, com foco nos objetivos e na estrutura.

- Discussão dos capítulos do livro Primavera silenciosa e da biografia da autora.

- Conexão do histórico do movimento ambiental com área Ciências Ambientais/PPGCTA.
}

Revbea, São Paulo, V. 15, № 6: 04-16, 2020.

revista brasileira 
Espaço pós-grupo: produção de texto com tema sobre a questão ambiental, enfocando os aspectos abordados na aula, atividade atribuída na plataforma Google Classroom.

Avaliação: realização das atividades nos espaços individual, do grupo e pós-grupo.

Atividade 2 - Agenda 2030 e objetivos do desenvolvimento sustentável (ODS)

Espaço individual: trabalho discente, visando reconhecer a importância dos ODS e apreciar a abrangência, bem como construir a atividade 4 de forma a produzir avanços na agenda 2030, contemplando a abordagem de algum/ns ODS.

- Leitura da agenda 2030 (referência 4), construção de slides sobre ODS (referências 5 a 21). Os discentes irão preparar coletivamente arquivo de Power Point com slides sobre os ODS. Os discentes se revezam na apresentação dos ODS e na condução da discussão subsequente.

Espaço do grupo: Aula síncrona na plataforma Google Meet, duração 3 horas.

- Apreciação da Agenda 2030 e dos ODS por meio de exposição dialogada com suporte de slides. Realizada em duas aulas de até 3 horas de duração cada uma.

Avaliação: realização das atividades nos espaços individual e do grupo e abordagem dos ODS na atividade 4.

Atividade 3 - Legislação ambiental e Política Nacional de Educação Ambiental

Espaço individual: trabalho discente, visando examinar a legislação ambiental e a Política nacional de Educação Ambiental (PNEA).

- Produção de listagem com o histórico das leis ambientais do Brasil e da abordagem da questão ambiental nas constituições do país (referência 23).

- Leitura da PNEA (referências 23 e 24), com conexões entre o texto da lei e o projeto de educação ambiental desenvolvido por eles.

Espaço do grupo: Aula síncrona na plataforma Google Meet, duração 3 horas.

- Apresentação pelos discentes do histórico das leis ambientais brasileiras.

- Abordagem e discussão da PNEA.

Espaço pós-grupo: trabalho discente para construção coletiva de texto sobre as leis ambientais e PNEA, com avaliação da abrangência, lacunas e efeitos concretos.

Avaliação: realização das atividades nos espaços individual e do grupo e entrega do trabalho coletivo, e abordagem da PNEA na atividade 4.

\section{Atividade 4 - Projetos/Propostas em Educação Ambiental para a educação básica \\ Espaço do grupo: Aula síncrona na plataforma Google Meet, duração 3 horas.}

- Apresentação pelos docentes do projeto "Aprendendo sobre o valor da biodiversidade da Caatinga e seus serviços ecossistêmicos no ensino escolar" e dos temas para os subprojetos, seguida de orientações sobre a estrutura e propostas.

- Temas sugeridos para os subprojetos:

1. A Caatinga (características históricas e edafoclimáticas, biodiversidade e importância)

2. Flora (diversidade, adaptações, importância, serviços ecossistêmicos)

3. Fauna - vertebrados (diversidade, adaptações, importância, serviços ecossistêmicos)

4. Fauna - invertebrados (diversidade, adaptações, importância, serviços ecossistêmicos)

5. Fungos (diversidade, adaptações, importância, serviços ecossistêmicos)

6. Interações planta-animais (exemplos, importância, serviços ecossistêmicos).

Espaço pós-grupo: trabalho discente, com orientação docente, visando criar uma proposta de jogo didático com temas da Caatinga, considerando também os ODS e a PNEA.

- Definição dos grupos de alunos, escolha dos temas dos subprojetos.

- Trabalho dos grupos: elaboração de subprojeto que inclua a proposição de jogo didático, tendo como temas a Caatinga, os ODS e a PNEA. Essa atividade é uma ação incluída nos objetivos específicos do projeto "Aprendendo sobre o valor da biodiversidade da Caatinga e seus serviços ecossistêmicos no ensino escolar". Os subprojetos visam produzir kits educacionais voltados à divulgação científica sobre o valor da biodiversidade da Caatinga e seus serviços ecossistêmicos. 
Espaço do grupo: Aula síncrona na plataforma Google meet, duração 3 horas.

- Apresentação das propostas dos subprojetos elaborados pelos grupos de estudantes.

- Discussão das ideias e propostas dos subprojetos.

Espaço pós-grupo: trabalho discente, com orientação docente, visando desenvolver a proposta de jogo didático, abrangendo temas da Caatinga, ODS e PNEA.

- Desenvolvimento e sistematização das propostas dos jogos didáticos, com registro do trabalho desenvolvido no formato de artigo.

Avaliação: Elaboração e desenvolvimento dos projetos, redação dos artigos e apresentação dos trabalhos na Semana Universitária 2020 da UPE.

\section{Fonte: Autoria própria.}

A atividade de elaboração e execução dos projetos de Educação Ambiental tornou possível colocar em prática a aprendizagem invertida, pois, em todo o processo, o estudante precisou apresentar uma postura ativa (Quadro 2). No momento inicial da atividade do projeto, foram apresentados aos discentes os temas propostos e buscaram-se possibilidades teóricas e práticas. Posteriormente, houve a discussão coletiva sobre a versão preliminar dos projetos nos espaços de aprendizagem, onde os alunos e professores apresentam ideias e conceitos, problematizando, sugerindo ajustes e agregando novas ideias. Por fim, a execução permitiu que os discentes desenvolvessem uma solução/produto baseado nos conteúdos teóricos, práticos e discussões. Dessa forma, todo o processo promoveu e propiciou o desenvolvimento de reflexão, autocrítica, responsabilidade, autoconsciência e autonomia aos alunos da pós-graduação. Esse desenvolvimento discente tornando-os protagonistas no processo ensino aprendizagem é o que se busca quando se inclui metodologias ativas na prática docente (DEMIREL 2016; DEBALD 2018).

Foram desenvolvidas sete propostas com temas abrangentes sobre a biodiversidade da Caatinga, sendo três recursos didáticos e quatro jogos (artigos subsequentes desta edição especial da RevBEA). O desenvolvimento incluiu a idealização da proposta, a construção do projeto e a realização do jogo e sistematização feita com a elaboração de artigo apresentando cada produto.

Dentre os recursos didáticos foram desenvolvidas três propostas, sendo uma cartilha sobre invertebrados da Caatinga, intitulada: "A cartilha como instrumento de apoio didático: uma abordagem sobre os invertebrados da caatinga"; uma sequência didática sobre interações e serviços ecossistêmicos da fauna e da flora, intitulada: "Interações ecológicas entre flora e fauna da Caatinga: uma proposta de sequência didática utilizando o recurso didático Kahoot"; e uma trilha de gamificação com a caracterização geral da Caatinga, intitulada: "BIOtinga: trilha de gamificação sobre a Caatinga".

Os quatro jogos didáticos estão descritos nos artigos intitulados: Jogo de tabuleiro Flora da Caatinga - conhecer para preservar; Fungolândia: jogo educativo de tabuleiro sobre a diversidade e importância dos fungos na Caatinga; Jogo Animacards Caatingueiros: conhecendo os animais vertebrados 
da Caatinga e entendendo sua importância; e A biodiversidade da fauna e da flora da Caatinga no cancioneiro regional.

Esses trabalhos produzidos podem contribuir para a inserção de metodologias ativas na educação básica, e para a formação continuada de professores, visto que estudos correlacionam a utilização dessas metodologias com as oportunidades de formação continuada de professores um fator limitante para o uso de metodologias ativas (BACICH; MORAN, 2018).

Além disso, considerando que essa proposta incluiu também o uso de TICs, ela pode contribuir para a inserção dessas ferramentas, pois de modo semelhante ao que se verifica para as metodologias ativas, também tem uso limitado pela necessidade de formação continuada. Além disso, a estrutura escolar deficitária e a resistência de professores às novas tecnologias fazem parte dos fatores limitantes (SOARES-LEITE; NASCIMENTO-RIBEIRO, 2012).

\section{Conclusões}

O relato de caso apresentado pode contribuir para a ampliação do conhecimento e servir de estímulo para a adoção de metodologias ativas no ensino superior. Enquanto os trabalhos discentes produzidos no âmbito da disciplina, apresentados nos artigos a seguir nessa edição da RevBEA, apresentam propostas elaboradas de jogos e recursos didáticos contribuem para a adoção de metodologias ativas na educação básica. Além disso, considerando que a proposta inclui o uso de TICs, pode contribuir também para sua inserção no processo educativo, pois sua utilização é limitada pela necessidade de formação continuada dos professores, pela estrutura escolar deficitária e pela resistência de professores às novas tecnologias.

A inversão realizada na disciplina foi considerada bem sucedida, pois houve envolvimento discente no processo de ensino-aprendizagem, sendo protagonistas dele, resultando em aprendizagem significativa. Foram necessários ajustes no decorrer do semestre, os quais foram feitos na base do diálogo e das interações estabelecidas entre docentes e com os discentes, sem perder o foco na aprendizagem. O sucesso foi medido principalmente pelos produtos, que foram os jogos e recursos didáticos, frutos do trabalho docente e discente na disciplina Educação Ambiental e Sustentabilidade, os quais poderão servir de instrumento de formação continuada para professores da educação básica, ou até mesmo serem usados na formação inicial, em cursos de licenciatura. A experiência foi positiva, mas resta concluir uma etapa final de aplicação dos jogos e recursos didáticos que foi impossibilitada em decorrência da pandemia provocada pela Covid-19.

O contexto da pandemia causada pela Covid-19, apesar da gravidade, colocou um desafio para a comunidade escolar mundial relacionado à continuidade das atividades de ensino, impondo aos professores a necessidade/obrigatoriedade/oportunidade de realizar formação continuada para adoção de metodologias ativas, inversão de sala de aula e apropriação 
das TICs. Esse trabalho é uma consequência, e até mesmo uma superação desse desafio por docentes e discentes do PPGCTA, tem potencial para contribuir (ou mesmo inspirar) para a inversão de salas de aula na graduação e pós-graduação.

\section{Agradecimentos}

Ao Programa de Pós-graduação em Ciência e Tecnologia Ambiental (PPGCTA) da Universidade de Pernambuco Campus Petrolina.

À Coordenação de Aperfeiçoamento de Pessoal de Nível Superior (CAPES), Brasil - Código de Financiamento 001.

À Fundação de Amparo a Ciência e Tecnologia do Estado de Pernambuco (FACEPE) pela concessão de bolsas e financiamento do projeto "Aprendendo sobre o valor da biodiversidade da Caatinga e seus serviços ecossistêmicos no ensino escolar" (FACEPE APQ - 0177-2.05/18).

\section{Referências}

ABEYSEKERA, L.; DAWSON, F. Motivation and cognitive load in the flipped classroom: definition, rationale and a call for research. Higher Education Research and Development, v. 34, n. 1, p. 1-14, 2015.

ANDERSON, L.W.; KRATHWOHL, D.R.; BLOOM, B.S. A taxonomy for learning, teaching, and assessing: a revision of Bloom's taxonomy of educational objectives. New York: Allyn \& Bacon. 2001.

BACICH, L.; MORAN, J. Metodologias ativas para uma educação inovadora: uma abordagem teórico-prática (Série Desafios da Educação), Porto Alegre: Penso, 2018. E-book.

CAMARGO, F.; DAROS, T. A sala de aula inovadora: estratégias pedagógicas para fomentar o aprendizado ativo (Série Desafios da Educação), Porto Alegre: Penso, 2018. E-book.

DEBALD, B. Metodologias ativas no ensino superior: o protagonismo do aluno (Série Desafios da Educação), Porto Alegre: Penso, 2018. E-book.

DEMIREL, E.E. Basics and key principles of flipped learning: classes upside down. International Journal of Languages, Literature and Linguistics, v. 2, n. 3, 2016. DOI: 10.18178/ijll.2016.2.3.77

FERRAZ, A.P.C. M.; BELHOT, R.V. Taxonomia de Bloom: revisão teórica e apresentação das adequações do instrumento para definição de objetivos instrucionais. Gest. Prod., v. 17, p. 421-431, 2010.

FLN - Flipped Learning Network. Definition of flipped learning. 2014. Disponível em: http://flippedlearning.org/definition-of-flipped-learning/. Acesso em: 17 jul. 2020. 
GUERRA, A.F.S., ORSI, R.F.M., STEUCK, E.R., SILVA, M.P., SERPA, P.R., SANTOS, B.C.L.S., ROCKETT, A.N. Educação Ambiental: a resistência e o esperançar em tempos de pandemia. Revista Brasileira de Educação Ambiental (RevBEA), v. 15, n. 4, p. 237-258, 2020. https://doi.org/10.34024/revbea.2020.v15.10794

LAGE, M.J.; PLATT, G.J.; TREGLIA, M. Inverting the classroom: a gateway to creating an inclusive learning environment. Journal of Economic Education, v. 31, n. 1 , p. 30-43, 2000.

LAYRARGUES, F.P.; LIMA, G.F.C. As macrotendências político-pedagógicas da educação ambiental brasileira. Ambiente e Sociedade v. XVII, n. 1, p. 2340, 2014.

LO, C.; HEW, K. A critical review of flipped classroom challenges in K-12 education: possible solutions and recommendations for future research. Research and Practice in Tecnology Enhanced Learning v. 12, n. 4, 2017. DOI: 10.1186/s41039-016-0044-2

O'FLAHERTY, J.; PHILLIPS, C. The use of flipped classrooms in higher education: a scoping review. The Internet and Higher Education, v. 25, p. 8595, 2015.

SOARES-LEITE, W.S.; NASCIMENTO-RIBEIRO, C.A. A inclusão das TICs na educação brasileira: problemas e desafios. Magis, Revista Internacional de Investigación en Educación, v. 5 n. 10, p. 173-187, 2012.

TALBERT, R. Guia para Utilização da Aprendizagem Invertida no Ensino Superior (Série Desafios da Educação), Penso: Porto Alegre, 2019. E-book.

TREVELIN, A.T.C.; PEREIRA, M.A.A.; OLIVEIRA NETO, J.D. A utilização da "sala de aula invertida" em cursos superiores de tecnologia: comparação entre o modelo tradicional e o modelo invertido "flipped classroom" adaptado aos estilos de aprendizagem. Revista de Estilos de Aprendizaje, v. 6, n. 12, p. 137-150. 2013.

VALENTE, J.A. Blended learning e as mudanças no ensino superior: a proposta da sala de aula invertida. Educar em Revista, v. 4, p. 79-97, 2014. 